\title{
Schematizing Insured Healthcare Dossiers in Cloud using Blockading Maneuver Sequence Amplification (BMSA)

\author{
K.Ketzial Jebaseeli, V.G Rani
}

\begin{abstract}
Blockade technology in healthcare industry captures the focus in the newfangled years. As a major development it has resulted in the inclusion even in marketing commerce. This progression has enriched the user preoccupied with pharmaceutical sector consequently endorsing possible manipulations and potentials. This conduct in blockading maneuver is done by calculating total file numerals through tokenization which subsequently processed by encryption. Whereas Cloud-Based Manufacturing delegates on-demand ingress to manufacturing stratagems, a reliable emissary is required for transactions between the users who aspire to suffice manufacturing services. Therefore it results in counting to the lines that are availed in an indicted block by the usage of that exacting value derived by division. The health records enclosed in a block is encrypted by blockading maneuver accordingly. In the previous works only permission is accessed to the user and encrypts the whole file. This concept of blockage advances in displaying contents in attendance and also permits to read the intact block. The files are stocked up in a block to encrypt them each. This method in endowing two strategies upshots in reducing decryption time. Ensuring data availability and uploading data by the user in encrypted form is scrutinized as a chief component in this line of attack.
\end{abstract}

Keywords: accession, Block chain, Block maneuver, item set, threshold value.

\section{INTRODUCTION}

Existing years as of now, security concerns are the foremost role in technology aspects. Security issues in healthcare witness an enormous data larceny these days. Segregating and sheltered accession of data through blocks is celebrated as a new technological insurgency. The knowledge of blockading maneuver can be used even for familial gross product percent. Conventional cloud storage has come up to rely almost utterly on outsized storage providers acting as conviction third parties to relocate and accumulate data[3]. These systems facades a number of inadequacies as well as the recital, availability, higher operation cost and refuge. The storage data through split blocks is incorporated in this system of blockading maneuver.

Revised Manuscript Received on December 30, 2019.

* Correspondence Author

K.Ketzial Jebaseeli*, Asst. Professor, IT Department, holder of the BCA degree from Bharathiar University, Tamilnadu, India.

Dr.V.G.Rani, Associate Professor, CS Department. Of Computer Science from Bharathiar University, Tamilnadu, India.

(C) The Authors. Published by Blue Eyes Intelligence Engineering and Sciences Publication (BEIESP). This is an open access article under the CC-BY-NC-ND license http://creativecommons.org/licenses/by-nc-nd/4.0/
The blocks are initially clutched out from files that are to be encrypted by use of keys further processing to blockading maneuver. Whichever two records are in admittance as patient and health records endures user classification that carry out split blocks. The data that are stored in each file is outgrowth two at a time. The files are in the main apportioned as general information and sensitive information. The blockading maneuver by the use of blocks is afore-thought as high security in user file category.

This paper encompasses block access that is blockading maneuver which is more secured and allows two configures,

- The content of each block is displayed

- The users are permitted to read entire block, Whereas, earlier versions of file storage indulge in accessing acquiescence to data users.

\section{RELATED WORKS}

P.Taylor (2006)[4] demonstrated that a block chain can also be focused on a financial overhaul that is entirely user-oriented acquiesces smart healthcare scheme for ameliorate of patients. The author mentioned end to end encryption of the user empowering block chain access in the system. The confluence of this technology can give highly meticulous emanations in terms of machine learning with the security and authenticity of Block chain Technology. This paper is a critique of how amalgamating these two technologies can uphold in healthcare sectors.

P. B. Nichol (2016) [5]conversed on the use of block chain in healthcare industry that confiscates cost and time. This methodology also elaborates a precise exertion of Keyless Signature Infrastructure (KSI) to endow endorsement on a ponderous balance. Global-scale corroboration at an incorruptibility embraces their coalesced confronts. This study enumerates time and reserves used up on verification of artisans' scrupulousness. The way of fleeting data uses personal ones which are enormously secured. Moreover, Noser Health (Germany) and Net cetera (Switzerland) have joined health bank as partners a short while ago to mature its global health data negotiation platform. This proposed scheme adds likeness in use of block chain in healthcare management.

O. Williams-Grut (2016)[6] promulgated dealing by Estonian e-health authority apace with systems that ascertain authority over Estonian information systems that budges technology. guardtime's 


\section{Schematizing Insured Healthcare Dossiers in Cloud using Blockading Maneuver Sequence Amplification (BMSA)}

This system modulates how block chain is engrossed into guard time that affords private network to citizens and also endows permission to access information and authenticate on it. Each update retrieved by the user and every access permitted to the owner in records of healthcare is chronicled in block chain which leads to prevailing security and makes it complicated for embezzlement of data in healthcare compartments. In this article, the author elucidates an additional name of block chain as distributed ledger technology. This technology assumes the post of a non-centralized database that in reality consents to hobnob of clients to sign off the data in access. Inspection is done in order to ensure the accuracy of each data accessed by the user which in turn signed off when segregated by complex cryptography.

K.Ketzial Jebaseeli, V.G.Rani (2016) [2] indicated the access of files from a group of users rather than accessing with the use of primary user. A group of signatures are formed in order to secure the files and alleviate quantum attacks. Formation of ring signature scheme paves way to increased security also to demoniacally forming group for data access using cryptographic expedients. The users can adit data solitarily

if it appeases attribute policy. This paper corroborates an ensemble signature scheme has been modeled to construct a ring signature for the dynamically establishing group by the data owner and generated signature is again secured using hashing technique.

K.Ketzial Jebaseeli, V.G.Rani (2016) [1] disinterred that the files can be given access and encrypted by using k-vertex keyword that is dynamically gauged out. A commensurate AES algorithm has been correlated for encryption of data. The data salvages artifice that has been left down on the basis of hierarchy of the data end user and a malleable revocation abrogate has been imparted to the data owners. Utterly, this paper shackles user profile classification in file access imputing k-vertex search scheme in key procreation.

\section{PROPOSED METHODOLOGY}

The proposed system uses block chain as the moral fiber for data storage access, permission endowment and token generation. Blockading maneuver portrays exertion of blocks through which the files are encrypted and accessed. The blockading maneuver permits the data user to opt for any block or read the entire set of blocks.

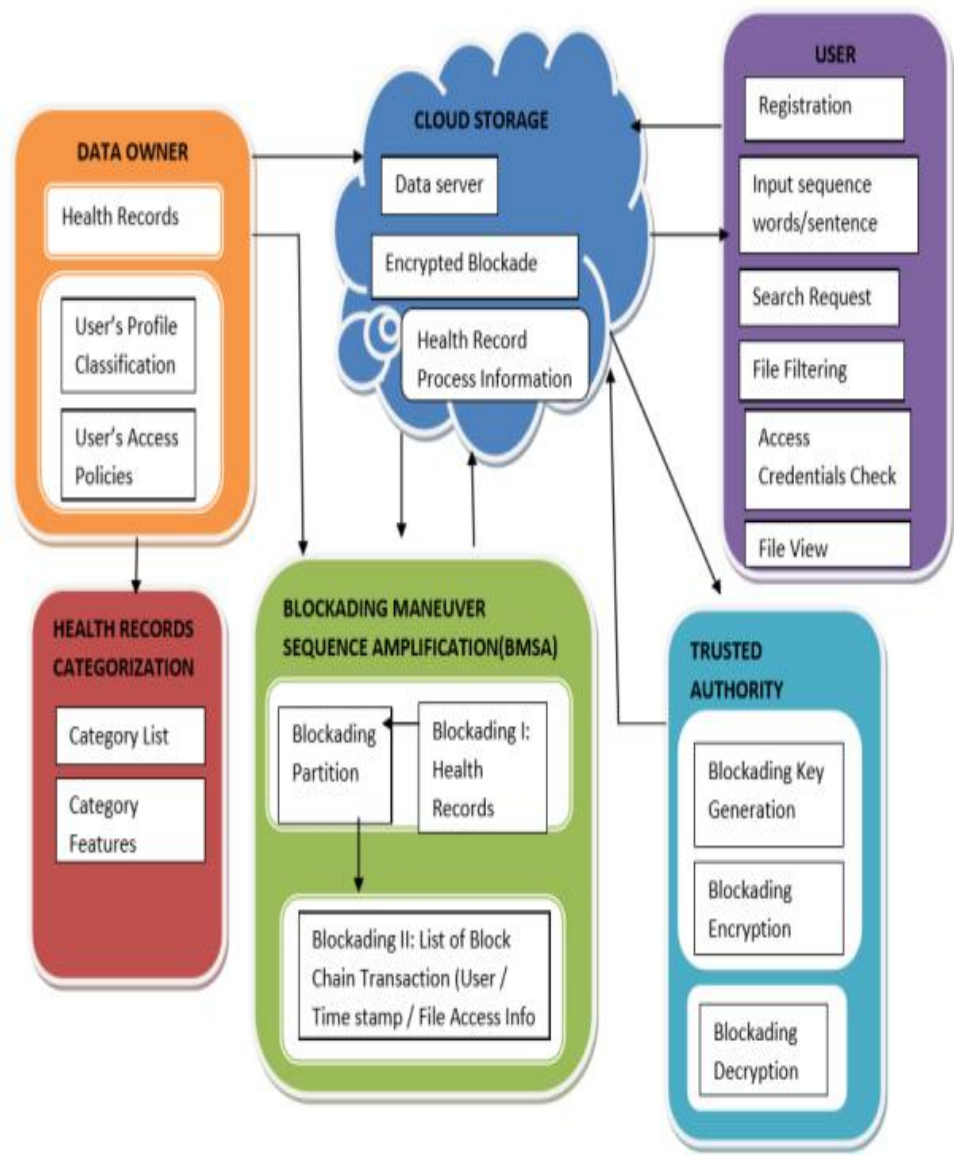

Fig 1. Overview of proposed methodology

From the framework that is put on view above evidently depicts the records that are categorized and accessed by data owner is then reassigned in cloud for storage. In the course of blockading maneuver, the blocks in cloud storage is detached as two files ensuing to encryption.

\section{A. Data Owner}

A compilation of health records are engrained in this entity. 
Blockading health records is contemplated as an exceeding mechanism in categorizing each file for encryption.

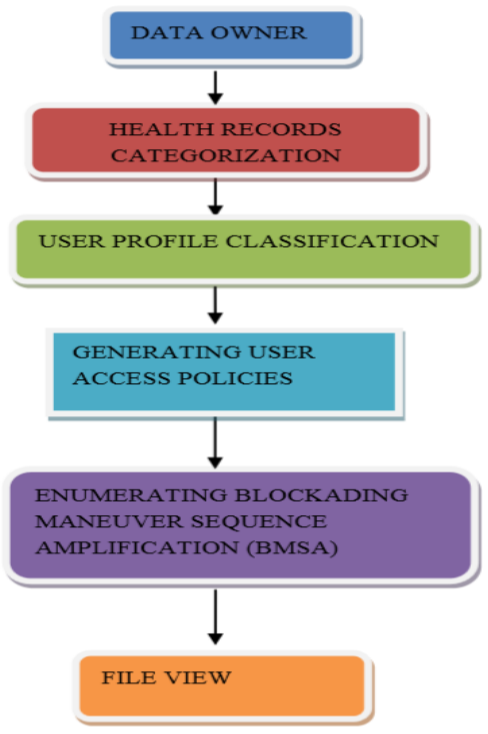

Fig.2 Phases of data owner to access file

The above figure 2 illustrates the primary portrayal of data owner. The records in healthcare industry are categorized through substructure of user apportionment profile in which the user is permitted to access files for encryption. The intact file is disjointed into blocks aftermath culminating to encryption process. Blockading Maneuver Sequence Amplification (BMSA) is recapitulated at this stage in order to access each file sentences. Accession of each file into blocks taking account of sentence is a dominant element in this methodology. Perceiving files by the owner depends on interpretation of file content or the whole unabridged file.

\section{B. Data User}

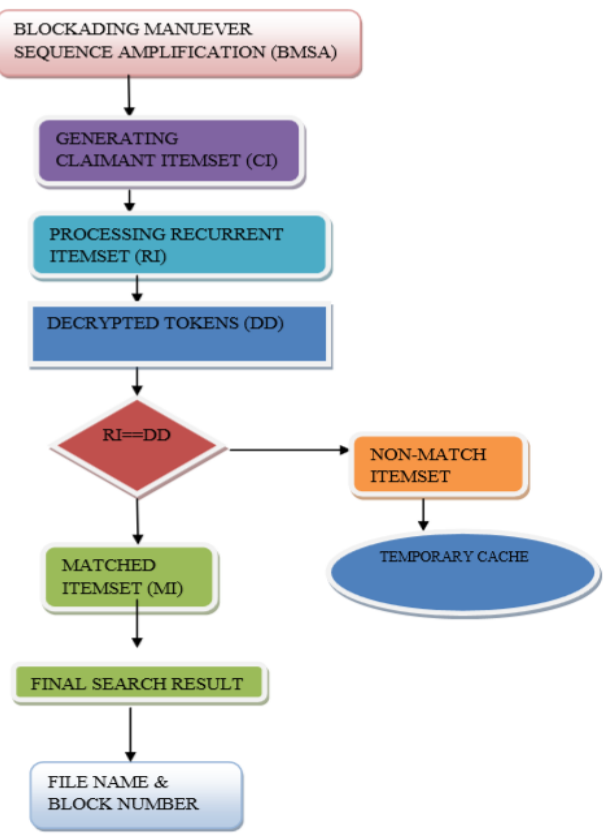

Fig.3. User accreditation of files by BMSA
From figure 3, the data user is incurred with two sets claimant item set and recurrent item set. The process access to generate from BMSA emanating through generation of claimant item set permitting access to recurrent item set that generates frequent item. Disbanding a sequence component intrinsically is claimant item set whereas taking up the sequence as a clump and generating it is recurrent item set. The two courses in this entity complies generation of token decryption. In case that value of recurrent item set coequals the tokens that are decrypted, the item set is envisaged as matched item set (MI). Howbeit, non-match item set not equal passing through temporary cache. The resulting search through matched item set (MI) is begot in the course of which file name and block number is pervaded.

\section{Cloud Storage}

Cloud server stockpiles the records accessed by the data server. The files that are carried out initially are encrypted all the way through blockading maneuver by ingression of each profile. Shortly, the encrypted blockade is glided away to trusted authority where the files are decrypted by assured keys [9]. The blockading maneuver that induces two or more files is processed as information as block access information or block access info.

\section{Trusted Authority}

The files that are commencing the data owner are consequently taken in by means of trusted authority where the key generation for the two supreme processes takes place. The accessed files are detached into blocks emanating to value the number of files for one block. This entity besets the key generation, encryption of data files hurled by the user and decryption of encrypted data files as well.

\section{E. Health Records Categorization}

On analogously cataloging the records in health profiles, they are category list and category features as profile classification is not necessitate to access files terminating by block accession. Category list implies the preeminent segment whence category features encompasses the components adduced in category list.

\section{BLOCKADING MANEUVER SEQUENCE AMPLIFICATION (BMSA)}

The impersonation of accessing sequence in blockading maneuver are ensued below

\section{A. Algorithm}

The Blockading Maneuver Sequence Amplification (BMSA) for accretion of files is instigated under the aegis of blocks by virtue of accessing intact file where the data is decrypted when the whole sequence matches with the decrypted tokens (RI=DD). Following are the peripherals of BMSA. 
STEP I: Key generation and reckon up of number of Lines (Li)

$\left(\mathrm{i}=1 ; \mathrm{L}_{\mathrm{i}} !=0 ; \mathrm{i}++\right)$

STEP II: Threshold value per block (Ti) ascribed STEP III: Formulate B $=\mathrm{Li} / \mathrm{Ti}$.

STEP IV: Value of B insinuates number of blocks. STEP V: Reformation of Block content into Hash Code.

STEP VI: Hash code is the key for encrypting the block.

The above algorithm exhibits accrediting files by initially estimating aggregate number of lines (Li) and for each block a value called threshold value (Ti) is stipulated (Li/Ti). The number of lines is counted up in key generation. The block content is indoctrinated as hash code exuding a key for the block file to be encrypted.

\section{B. Key Generation}

Key beget in file access induces bifurcation of claimant item set $(\mathrm{Ci})$ and recurrent item set (Ri). Branching each sequence to disparate modules by imploring token decryption.

ConveneCk=Encrypt(Concat(L11\#L12\#L21\#L22\#L31\#L32. .....Ln1\#Ln2)

Key for Encryption = Blockading Maneuver Sequence Amplification (BMSA)

Claimant Item set $=\mathrm{Ci}$

Recurrent Item set $=\mathrm{Ri}$

Key generation function concat is the files when apportioned in the group and generated string is encrypted using AES algorithm exploiting the ring signature as key. These aggregate key is used to unravel the file.[8]

\section{Decryption Mechanisms}

The outgrowth in decryption mechanism encounters key generation segregation of blocks in an unceasing sequence. The phases pass through with two main tiers, recurrent and claimant that which matched perpetuates into the formulation of value engender.

\section{- Data Encryption using AES}

The data encryption engaging symmetric key algorithm aspersed as Advanced Encryption Standard (AES) undergoes subsequent steps to induce the cipher text to the manuscript collection i. Sub byte is that a Byte is distorted not beyond hexadecimal digits [7].

\section{- Access key} up lines $\left(\mathrm{L}_{\mathrm{i}}\right)$

Step 1: String concatenation process for summing

Step 2: Referred to the sets in each sequence.

Threshold value $\left(\mathrm{T}_{\mathrm{i}}\right)$ by Lines $\left(\mathrm{L}_{\mathrm{i}}\right), \mathrm{T}_{\mathrm{i}}=\mathrm{L}_{\mathrm{i}}-$ matched item set.

\section{Set Up}

It is used to set up the public item sets by attaining the number of data sequences $\left(\mathrm{L}_{\mathrm{i}}\right)$ and parameters with threshold value $\left(\mathrm{T}_{\mathrm{i}}\right)$.

\section{EXPERIMENTAL RESULTS}

The tentative results have been premeditated by the performance in contrast with consequent lines engendered and the performance estimation between the numbers of keywords begotten. The encryption and decryption values are therefore correlated by the value elicited in accordance with threshold values. Analyzing security of the propounded model alongside an assortment of data size has been computed and described in terms of performance charts and tables for varied security performance measure akin to decryption time, conspiracy resistance and memory convention.

\section{A. Experimental Setup}

The experimental corollaries are pocketed with an Intel Core I3 central processing unit with 2620 Mainframes (2.0 GHz) and 4 GB RAM and 500 GB Winchester drive using Dot net programming. The directory server and file menial has been entrenched in the file entity which acts as Cloud underpinning. The contrastive file sizes are used for summation of prowess of the model. Proxy server has been ingrained using virtualization outgrowth as Virtual contrivance.

\section{B. Performance Inquisition}

The fidelity of the system is expounded in terms of idolization of attorney server machinery in data partaking systems to taper down the decryption time of the group members. It will significantly smooth the progress of data proprietor consigned the ingression rights to additional members.

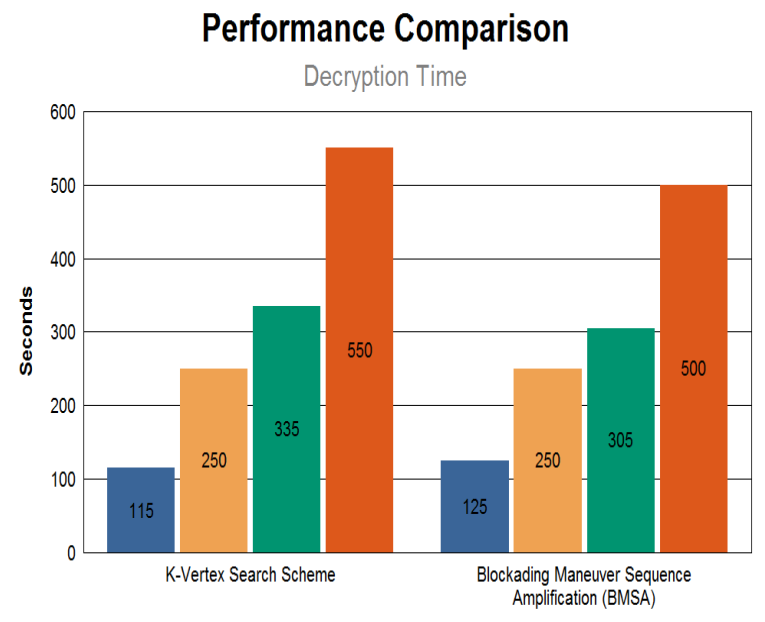

Fig.4. Performance comparison of decryption time with preceding method 
The above given figure 4 connotes the overall decryption time taken by k-vertex search scheme and Blockading Maneuver Sequence Amplification (BMSA). By comparing both schemes, BMSA has taken the least depicted in the graph accordance with seconds instigating from zero. Despite the fact that only a minimal change is perceived, BMSA is the finest in decoding by total time taken.

Table - I: Decryption Seconds of K-Vertex Search Scheme, BMSA

\begin{tabular}{|c|c|c|c|c|}
\hline Method & $\begin{array}{c}\text { Health } \\
\text { Records_10 } \\
\text { _Files } \\
\text { in Seconds }\end{array}$ & $\begin{array}{c}\text { Health } \\
\text { Records_40 } \\
\text { Files } \\
\text { in Seconds }\end{array}$ & $\begin{array}{c}\text { Health } \\
\text { Records_70 } \\
\text { Files } \\
\text { in Seconds }\end{array}$ & $\begin{array}{c}\text { Health } \\
\text { Records_10 } \\
\text { 0_Files } \\
\text { in Seconds }\end{array}$ \\
\hline $\begin{array}{c}\text { K-Vertex } \\
\text { Search } \\
\text { Scheme }\end{array}$ & 115 & 250 & 335 & 550 \\
\hline $\begin{array}{c}\text { Blockadi } \\
\text { ng } \\
\text { Maneuve } \\
\text { r } \\
\text { Sequenc } \\
\text { e } \\
\text { Amplific } \\
\text { ation } \\
\text { (BMSA) }\end{array}$ & $\mathbf{1 2 5}$ & $\mathbf{2 5 0}$ & $\mathbf{3 0 5}$ & $\mathbf{5 0 0}$ \\
\hline
\end{tabular}

Augmentation of files in decryption is additional in number by BMSA than K-vertex search scheme. This methodology of BMSA clutches more in memory and also deflates time taken to decrypt. Even when number of files is enormous in number, the seconds to decode each file in health records are comparatively low than K-vertex search scheme.

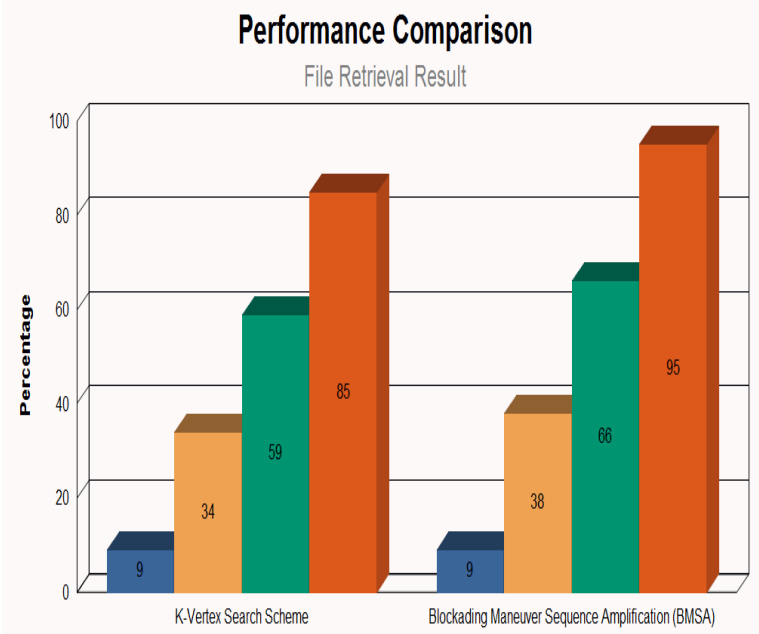

Fig. 5. Performance comparison in File Retrieval

From the given figure 5 it is obvious that the percentage of file retrieved is elevated. The percentage commences from zero to the replete. Preceding proposal K- vertex search scheme is pointing towards a lesser retrieval of files in percentage feature than the contemplated technology, BMSA. The accession of files in BMSA is begot by the user in an agile and more insured way.

Table- II: File Retrieval Result of K-Vertex Search Scheme, BMSA

\begin{tabular}{|l|r|r|r|r|}
\hline Method & $\begin{array}{c}\text { Health } \\
\text { Records_10 } \\
\text { Files } \\
\text { in } \\
\text { Percentage }\end{array}$ & $\begin{array}{c}\text { Health } \\
\text { Records_40 } \\
\text { Files } \\
\text { in } \\
\text { Percentage }\end{array}$ & $\begin{array}{c}\text { Health } \\
\text { Records_70 } \\
\text { Files } \\
\text { in } \\
\text { Percentage }\end{array}$ & $\begin{array}{c}\text { Health } \\
\text { Records_10 } \\
\text { 0_Files } \\
\text { in } \\
\text { Percentage }\end{array}$ \\
\hline $\begin{array}{l}\text { K-Vertex } \\
\text { Scheme }\end{array}$ & $9 \%$ & $34 \%$ & $59 \%$ & $85 \%$ \\
\hline $\begin{array}{l}\text { Blockadi } \\
\text { ng } \\
\text { Maneuve } \\
\text { r } \\
\text { Sequenc } \\
\text { e } \\
\text { Amplific } \\
\text { ation } \\
\text { (BMSA) }\end{array}$ & $\mathbf{9 \%}$ & $\mathbf{3 8 \%}$ & $\mathbf{6 6 \%}$ & \\
\hline
\end{tabular}

\section{Performance Comparison}

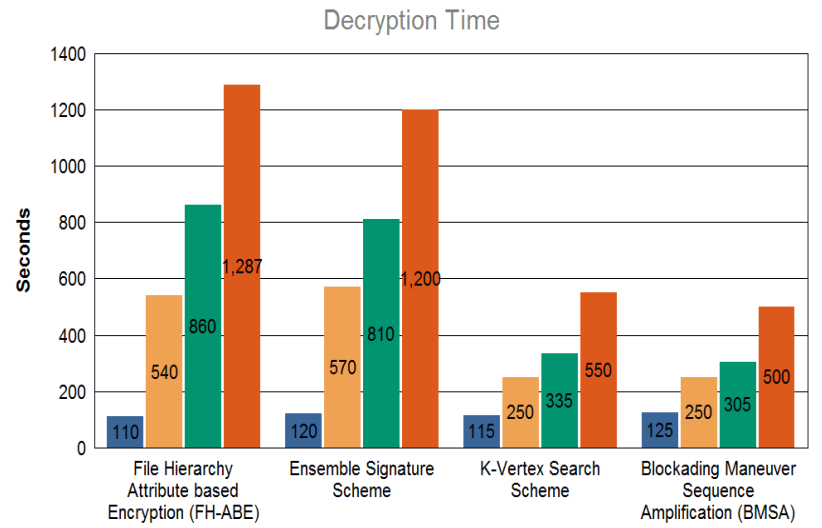

Fig.6. Decryption time comparison with preceding researches

From figure 6 it is evidently illustrated that the time being taken for each accretions delineated in seconds as in file hierarchy attribute based, ensemble signature, k-vertex search scheme and BMSA. Interpolated of all the preceding methods, BMSA takes the meanest passel of time for decryption which progressively reduces the security intimidation observed by the users. Negligible decryption time results in the encroachment of data security to its crest. The contradicting matches of each proposal are specified in Figure 6. The proposed technique BMSA is shown the minimum in the graph connoting the minimum time taken in disentangling the encrypted data. 
Schematizing Insured Healthcare Dossiers in Cloud using Blockading Maneuver Sequence Amplification (BMSA)

Table - III: Overall Decryption Seconds of FH-ABE, Ensemble Signature Scheme, K-Vertex Search Scheme, BMSA

\begin{tabular}{|c|c|c|c|c|}
\hline Methodology & $\begin{array}{c}\text { Health } \\
\text { Records_10 } \\
\text { Files } \\
\text { in seconds }\end{array}$ & $\begin{array}{c}\text { Health } \\
\text { Records } \\
40- \\
\text { Files } \\
\text { in } \\
\text { seconds }\end{array}$ & $\begin{array}{c}\text { Health } \\
\text { Records_ } \\
70- \\
\text { Files } \\
\text { in } \\
\text { seconds }\end{array}$ & $\begin{array}{c}\text { Health } \\
\text { Records } \\
100 \\
\text { _Files } \\
\text { in seconds }\end{array}$ \\
\hline $\begin{array}{l}\text { File Hierarchy } \\
\text { Attribute based } \\
\text { Encryption } \\
\text { (FH-ABE) }\end{array}$ & 110 & 540 & 860 & 1287 \\
\hline $\begin{array}{l}\text { Ensemble } \\
\text { Signature } \\
\text { Scheme }\end{array}$ & 120 & 570 & 810 & 1200 \\
\hline $\begin{array}{l}\text { K-Vertex } \\
\text { Search Scheme }\end{array}$ & 115 & 250 & 335 & 550 \\
\hline BMSA & 125 & 250 & 305 & 500 \\
\hline
\end{tabular}

The table on top portrays the time taken to decode files in accordance with the number of files that are decrypted. The proffered scheme BMSA authenticated the slightest number judged against with all the three proposals.

Performance Comparison

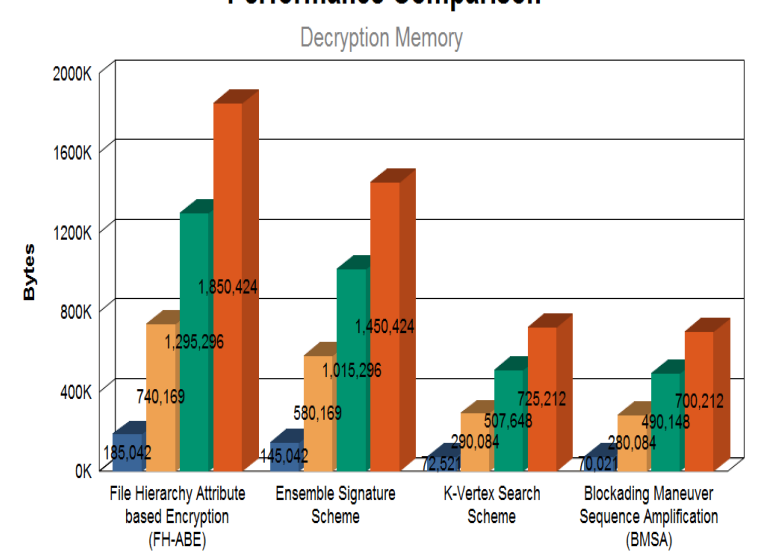

Fig.7. Performance comparison of memory storage

From the above depicted figure the bytes denoted compared with the preceding proposals that are put into use. The statistical description accords that BMSA is excogitated as most avant-garde in memory storage as other methodologies. The files of diverse sizes are being hoarded in each memory to ingress files from the user and owner and vice versa.

The exactitude is given in the file accredit with the mode of operations muddled and the health records accessed in bytes. The number of records in health article fluctuates acquiesced to the methodologies that are effectuated. The memory storage in the proposed system is immense comparing with other three antecedent methodologies implemented. This pinpoints that BMSA can be used for superior memory storage.
Table IV: Decryption Memory Comparison of FH-ABE, Ensemble Signature Scheme, K-Vertex Search Scheme, BMSA

\begin{tabular}{|c|c|c|c|c|}
\hline Methodology & $\begin{array}{l}\text { Health } \\
\text { Records_ } \\
\text { 10_Files } \\
\text { in Bytes }\end{array}$ & $\begin{array}{l}\text { Health } \\
\text { Records } \\
\text { 40_Files } \\
\text { in Bytes }\end{array}$ & $\begin{array}{l}\text { Health } \\
\text { Records_ } \\
\text { 70_Files } \\
\text { in Bytes }\end{array}$ & $\begin{array}{l}\text { Health } \\
\text { Records } \\
100 \_ \text {Files } \\
\text { in Bytes }\end{array}$ \\
\hline $\begin{array}{l}\text { File Hierarchy } \\
\text { Attribute } \\
\text { based } \\
\text { Encryption } \\
\text { (FH-ABE) }\end{array}$ & 185,042 & 740,169 & $1,295,296$ & $1,850,424$ \\
\hline $\begin{array}{l}\text { Ensemble } \\
\text { Signature } \\
\text { Scheme }\end{array}$ & 145,042 & 580,169 & $1,015,296$ & $1,450,424$ \\
\hline $\begin{array}{l}\text { K-Vertex } \\
\text { Search } \\
\text { Scheme }\end{array}$ & 72,521 & 290,084 & 507,648 & 725,212 \\
\hline $\begin{array}{l}\text { Blockading } \\
\text { Maneuver } \\
\text { Sequence } \\
\text { Amplification } \\
\text { (BMSA) }\end{array}$ & 70,021 & 280,084 & 490,148 & 700,212 \\
\hline
\end{tabular}

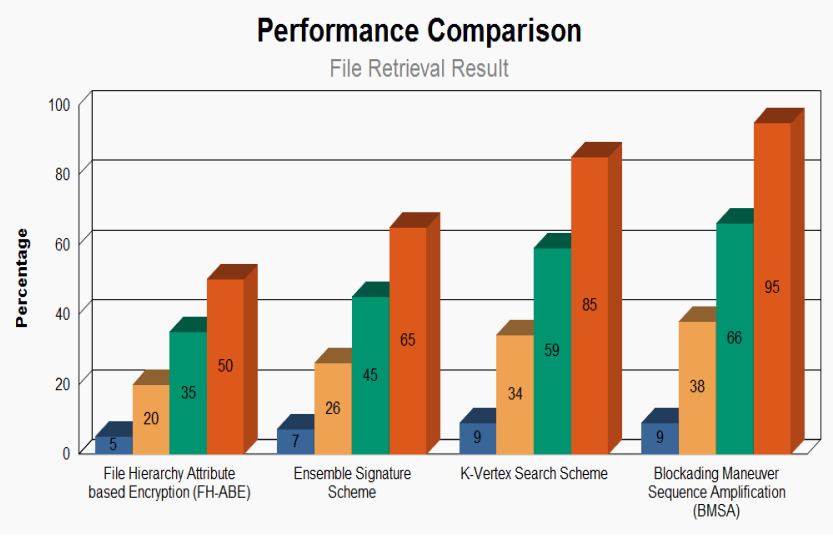

Fig.8. Comparing files retrieval results

From the given figure 8 it is obvious that the percentage of file retrieved is elevated. The percentage commences from zero to the replete. Each tactics is progressively high out setting from file hierarchy attribute based encryption to blockading maneuver sequence amplification (BMSA). 
Table V: File Retrieval Result of FH-ABE, Ensemble Signature Scheme, K-Vertex Search Scheme, BMSA

\begin{tabular}{|c|c|c|c|c|}
\hline $\begin{array}{l}\text { Methodolog } \\
\text { y }\end{array}$ & $\begin{array}{l}\text { Health } \\
\text { Records__ } \\
10 \_ \text {Files } \\
\text { in } \\
\text { percentag } \\
\text { e }\end{array}$ & $\begin{array}{l}\text { Health } \\
\text { Records__ } \\
\text { 40_Files } \\
\text { in } \\
\text { percentag } \\
\text { e }\end{array}$ & $\begin{array}{l}\text { Health } \\
\text { Records__ } \\
\text { 70_Files } \\
\text { in } \\
\text { percentag } \\
\text { e }\end{array}$ & $\begin{array}{l}\text { Health } \\
\text { Records__ } \\
100 \_ \text {Files } \\
\text { in } \\
\text { percentag } \\
\text { e }\end{array}$ \\
\hline $\begin{array}{l}\text { File } \\
\text { Hierarchy } \\
\text { Attribute } \\
\text { based } \\
\text { Encryption } \\
\text { (FH-ABE) }\end{array}$ & $5 \%$ & $20 \%$ & $35 \%$ & $50 \%$ \\
\hline $\begin{array}{l}\text { Ensemble } \\
\text { Signature } \\
\text { Scheme }\end{array}$ & $7 \%$ & $26 \%$ & $45 \%$ & $65 \%$ \\
\hline $\begin{array}{l}\text { K-Vertex } \\
\text { Search } \\
\text { Scheme }\end{array}$ & $9 \%$ & $34 \%$ & $59 \%$ & $85 \%$ \\
\hline $\begin{array}{l}\text { Blockading } \\
\text { Maneuver } \\
\text { Sequence } \\
\text { Amplificatio } \\
\text { n } \\
\text { (BMSA) }\end{array}$ & $9 \%$ & $38 \%$ & $66 \%$ & $95 \%$ \\
\hline
\end{tabular}

Health Records as files are retrieved from user as shown in the above table. Each file is accessed aftermath the generation of keyword sequence preeminent to salvaging of each file by the user. The percentage of file retrieval is deliberately inflated in assimilation to the previous investigations. The health records in each entity corresponding to the schemes are added up culminating in a superlative percent in BMSA.

\section{CONCLUSION}

The intended conception derives the use of blocks that are accessed in files partitioned by each sequence or sentence detachment. Files that are accessed are secluded in which decryption keys are engendered. This method Block Maneuver Sequence Amplification induces severance of each segment or file and then accessing it to decryption block. Summation of values for one block is reckoned for the value obtained in the absolute block. Consequently categorized item sets are put in use for the gauging of threshold values paving way for adaptation of content in block to hash code form where the values are being procreated. In BMSA, estimation of each block is undemanding additionally saving time taken for decryption along with memory repository in metaphor with Ensemble signature and K-vertex search scheme. File accession are secluded into blocks whereas ensemble embraces a cluster of users to decode the given file. Experimental results make palpable the effectiveness and accurateness of our projected scheme on a variety of procedures.

\section{REFERENCES}

1. K.Ketzial Jebaseeli, Dr.V.G.Rani, "A Lightweight Data Preserving model using Ensemble Signature Scheme to the Outsourced health files in cloud", Journal of Advanced Research in Dynamical and Control Systems,Vol.11,02-Special Issue,2019

2. K.Ketzial Jebaseeli, Dr.V.G.Rani,"Accessing Dynamic Health Records using K-Vertex Search Scheme Model towards Hierarchical Users Mod Obscure Servers", International Journal of Recent Technology and Engineering",Vol.8,Issue 03,pp.34743479,Sep.2019

3. J. Zhang, N. Xue, and X. Huang, "A secure system for pervasive social network-based healthcare," IEEE Access, 2016

4. P. Taylor (2016, April), Applying blockchain technology to medicine traceability, [Online]. Available: https://www.securingindustry.compharmaceuticals/applyingblockchain-technology-tomedicinetraceability/s40/a2766/\#.V5mxL_mLTIV.

5. P. B. Nichol (2016, March), Blockchain applications for healthcare,[Online].

Available:http://www.cio.com/article/3042603/innovation/ blockchain-applications-for-healthcare.html.

6. O. Williams-Grut (2016, March), Estonia is using the technology behind bitcoin to secure 1 million health records, [Online]. Available:http://www.businessinsider.com/guardtime-estonianhealth-recordsindustrial-blockchain-bitcoin-2016-3?r=UK\&IR=T

7. NIST, FIPS PUB 197, "Advanced Encryption Standard(AES)," November $2001 \quad$ [Online]. Available: http://csrc.nist.gov/publications/fips/fips197/fips-197.pdf.

8. "Cloud Security and Privacy", Tim Mather, Subra

9. Kumaraswamy, and Shahed Latif - O'Reilly Book. M. Swan, Blockchain: Blueprint for a new economy. O'Reilly Media,Inc., 2015.

\section{AUTHORS PROFILE}

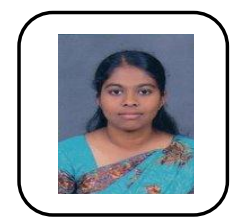

K.KETZIAL JEBASEELI BCA, MCA Asst. Professor, IT Department, holder of the BCA degree from Bharathiar University in 2008 and received MCA degree from Anna University in 2011. She is trailing her PhD in computer science at Sri Ramakrishna College for women. She has a practice of experience in her teaching for about 5 years. She has published papers in International journals and also presented papers in various International National and National level conferences.

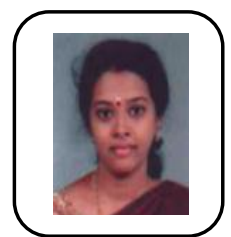

DR.V.G.RANI MCA., Ph.D., Associate Professor, CS Department. She received her Ph.D in Computer Science from Bharathiar University for the period of 2013. She is embraced with her master's degree in MCA and Bachelor degree in computer Science from Bharathiar University. Her scholastic in Sri Ramakrishna CAS for women has attained for about 16 years. Ad Hoc network, Security solution, Cloud computing and IoT are her research areas. She has showed her guidance towards 10 M.Phil scholars and at present $2 \mathrm{PhD}$ scholars are pursuing under her guidance. She has brought out further 10 papers in national and international conferences. Her publication of journal includes Scopus and IEEE. 